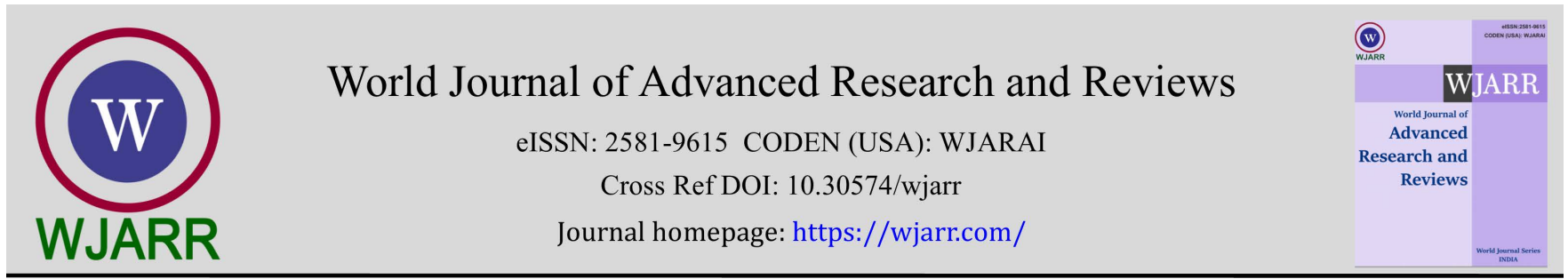

(RESEARCH ARTICLE)

\title{
Structural and optical property studies on Fe doped $\mathrm{CuO}$ nanoparticles
}

\author{
Kumara Dhas $\mathrm{M}^{1, *}$ and Vijayaraj $\mathrm{K}^{2}$ \\ ${ }^{1}$ Department of Physics, Amrita College of Engineering and Technology, Nagercoil, Tamil Nadu, India-629001. \\ 2 Department of Chemistry, Nadar Mahajana Sangam S. Vellaichamy Nadar College, Nagamalai, Madurai-625 019, India.
}

World Journal of Advanced Research and Reviews, 2022, 13(01), 203-209

Publication history: Received on 05 November 2021; revised on 28 December 2021; accepted on 30 December 2021

Article DOI: https://doi.org/10.30574/wjarr.2022.13.1.0683

\begin{abstract}
The Cupric oxide ( $\mathrm{CuO}$ ) nanostructures and Fe doped $\mathrm{CuO}$ nanomaterials are synthesized by microwave irradiation method. The effect of Fe doping on the crystal structure, band gap and optical properties of synthesized samples were characterized by using x-ray diffraction, ultraviolet-visible spectrometer, photoluminescence spectrometer and Fourier transform infrared spectrometer. X-ray diffraction study confirms the size of the particle in nanometer. The optical band gap calculated from UV-Vis absorption spectrum, reveals the change in band gap energy due to the presence of dopants. The photoluminescence spectrum suggests that Fe doped $\mathrm{CuO}$ nanoparticles may be used in optoelectronic devices. The functional group analysis carried out by Fourier transform infrared spectroscopy confirmed the substitution of Fe in the samples.
\end{abstract}

Keywords: Nano particles; $\mathrm{CuO}$ nano structures; Band gap

\section{Introduction}

Cupric oxide $(\mathrm{CuO})$ is an interesting semiconductor for their physical properties, inexpensive, abundant, and non-toxic [1-5]. CuO has been used in several applications such as gas sensors, electrodes, solar cells, photocatalysts, among others [6-10], Cupric oxide exhibits p-type conductivity, crystallizes in the monoclinic structure and has a low band gap [11]. Ponnar et.al. investigated the crystal structure, electrochemical, optical and magnetic properties effect of Ce doped with $\mathrm{CuO}$ nanostructures, synthesized by microwave irradiation method [12]. Vimala devi et.al. reported the effect of annealing and doping on the structural and optical properties of monoclinic undoped and Tb doped CuO [13]. The doping indicates the formation of single-phase monoclinic structure and also confirmed that Fe ions successfully incorporated into $\mathrm{CuO}$ crystal lattice by occupying $\mathrm{Cu}$ ionic sites [14].

The investigation on optical properties of undoped and $\mathrm{Sn}$ doped $\mathrm{CuO}$ results that the undoped $\mathrm{CuO}$ exhibits a stronger anticancer activity as compared to $\mathrm{Sn}$ doped $\mathrm{CuO}$ nanostructures [15]. The doping also affected the structural and optical properties of $\mathrm{CuO}$, which indicates the increased value of dopant led to a red-shift of a band gap from 1.33 to $1.18 \mathrm{eV}$ [16]. Rayapa Reddy et al. examined the structural and optical properties of $\mathrm{CuO}$ nanoparticles, synthesized by environmentally benign green route with copper acetate precursor using Caloropis procera leaf extract [17]. Vimala Devi et al. successfully prepared pure and La doped $\mathrm{CuO}$ by solution combustion synthesis and annealed at different temperature, which shows the effect of annealing temperature and dopant concentration on lattice defect, which indicates La ion in $\mathrm{CuO}$ reduces the crystallite size in $\mathrm{CuO}$ [18]. The rare-earth metal, Er doped MgO shows that annealing at high temperature, increases the sizes of nano-crystallites [19].

$\mathrm{CuO}$ has much importance in different fields because it is eco-friendly, cost-effective, and exhibits favorable characteristics [20]. The microwave irradiation method is chosen for the present work because of it's simple and novel

\footnotetext{
${ }^{*}$ Corresponding author: Kumara Dhas M

Department of Physics, Amrita College of Engineering and Technology, Nagercoil, Tamil Nadu, India-629001.

Copyright $(2022$ Author(s) retain the copyright of this article. This article is published under the terms of the Creative Commons Attribution Liscense 4.0.
} 
method and it requires a less time for the synthesis of nanoparticles. The CuO nanoparticles with different concentrations of Fe dopant and their structural, optical, properties have been reported in this work.

\section{Material and methods}

\subsection{Materials}

The copper (II) sulfate pentahydrate $\left[\mathrm{CuSO}_{4} 5 \cdot \mathrm{H}_{2} \mathrm{O}\right]$, Sodium hydroxide $[\mathrm{NaOH}]$, Ferrous sulphate heptahydrate $\left[\mathrm{FeSO}_{4} .7 \mathrm{H}_{2} \mathrm{O}\right]$ and ethanol $\left[\mathrm{C}_{2} \mathrm{H}_{2} \mathrm{OH}\right]$ were used for the synthesis of Fe doped $\mathrm{CuO}$ nanoparticles discussed in this work. The double distilled water and ethanol were used as solvents for the sample synthesis, the weight percentage has been followed as $\mathrm{x}=0,0.05$ and 0.1 refers 0,5 , and $10 \mathrm{wt} \%$ of Fe dopant.

\subsection{Synthesis of $\mathrm{CuO}$ and Fe doped $\mathrm{CuO}$ nanoparticles}

The pure and Fe doped $\mathrm{CuO}$ nanoparticles were synthesized by means of microwave irradiation method. In a typical synthesis of $\mathrm{CuO}$ nanoparticles $1 \mathrm{~g}$ of copper (II) sulfate pentahydrate and $0.5 \mathrm{~g}$ of sodium hydroxide were dissolved separately in $10 \mathrm{ml}$ deionized water and magnetically stirred for 3 hours, to obtain a clear transparent solution. It was then poured into a silica crucible, and placed in a domestic microwave oven and exposed to the microwave energy, 2.45 $\mathrm{GHz}$, multimode cavity, $750 \mathrm{~W}$ for $10 \mathrm{~min}$. A great amount of dark brown precipitation formed. After cooling to room temperature, obtained samples were thoroughly washed using double distilled water and ethanol for nearly five times to remove the unwanted impurities. The same procedure was adopted force doped $\mathrm{Cu}_{1-\mathrm{x}} \mathrm{Fe}_{\mathrm{x}} \mathrm{O}$ (with $\mathrm{x}=0,0.05$ and 0.1 ) samples. Doping was achieved by adding the appropriate amount of Ferrous sulphate heptahydrate (in wt\%). Finally, the samples were dried in a hot air oven and then annealed at $400{ }^{\circ} \mathrm{C}$ for 5 hours a muffle furnace to get the good crystallites [21].

\subsection{XRD Characterization}

The structural nature of the synthesized $\mathrm{Cu}_{1-\mathrm{x}} \mathrm{Fe}_{\mathrm{x}} \mathrm{O}(\mathrm{x}=0.0,0.05$ and 0.1$)$ samples were detailed by powder $\mathrm{X}$-ray diffraction method (XRD) using a Philips PW-1710 X-ray diffractometer with CuK radiation $(\lambda=1.54056 \AA ̊ \Omega)$ in the range of $10-80^{\circ}$ at room temperature.

\subsection{FTIR spectra}

To identify the functional groups and to confirm the substitution of Fe ions, the samples were scrutinized with Fourier Transform Infrared Spectrometer (FTIR; RX1 PERKINELMER: USA) at a resolution, $2 \mathrm{~cm}^{-1}$.The measurements were performed in the region between 400 and $4000 \mathrm{~cm}^{-1}$ using $\mathrm{KBr}$ as the beam splitter.

\subsection{UV-Vis spectra}

A Shimadzu UV-3600 UV-Vis-NIR spectrophotometer (Shimadzu Scientific Instruments, Columbia, MD) was used for absorption spectra measurements in the wavelength range of 250-1100 nm.

\subsection{Photoluminescence}

The photoluminescence (PL) spectrum was recorded at room temperature with an F-4500 PL spectrophotometer, 150W xenon lamp. Excitation wavelength has been fixed from the UV-Vis absorption spectrum.

\section{Results and discussion}

\subsection{Structural analysis}

XRD pattern of $\mathrm{Cu}_{1-\mathrm{x}} \mathrm{Fe}_{\mathrm{x}} \mathrm{O}(\mathrm{x}=0.0,0.05$ and 0.1$)$ nanoparticles is shown in Figure 1 . Two, more or less equal intensity peaks were recorded at $2 \theta=35.55$ and $38.77^{\circ}$ corresponding to $(-111)$ and (111) planes which are the characteristics peaks of monoclinic phase of $\mathrm{CuO}$ samples. The entire diffraction pattern matches well with the JCPDS data card No. 050661 of $\mathrm{CuO}$ nanoparticles [22] with a space group of $\mathrm{C} 2 / \mathrm{c}$. The other peak related to impurity or secondary phases present in the samples. It should be noted that the increase in dopant concentration affects the intensity of diffraction peaks but not the crystal structure. It can be seen that the intensity of (111) peak is comparatively higher than that of $(-111)$ peak, this increases in peak intensity with dopant concentration confirmed the presence of Fe into CuO host lattice. The average crystallite size was calculated by using Debye-Scherrer equation [23]. as given below 


$$
D=\frac{0.9 \lambda}{\beta \cos \theta}
$$

where $\beta$ denotes full width at half maximum (FWHM) of the highest intensity peak, $\theta$ is diffraction angle and $\lambda$ is the wavelength of incident $\mathrm{x}$-ray beam $(1.541 \AA$ ) .
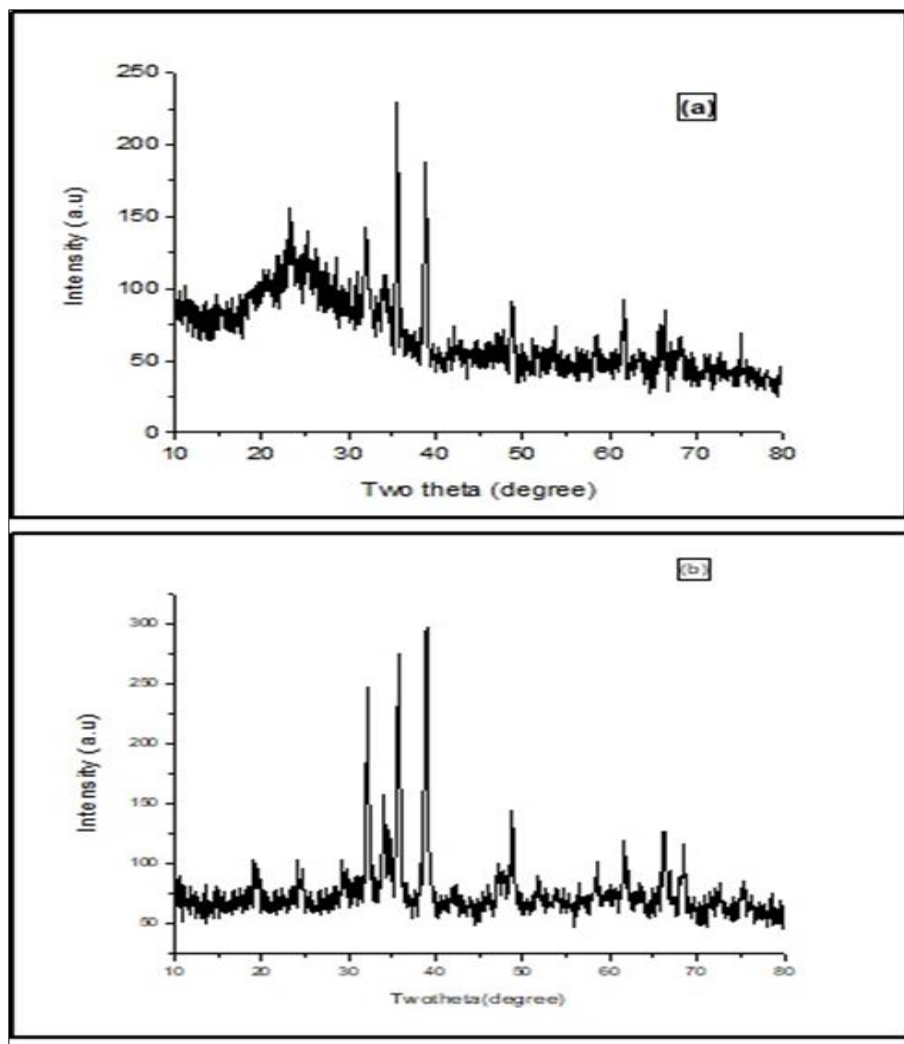

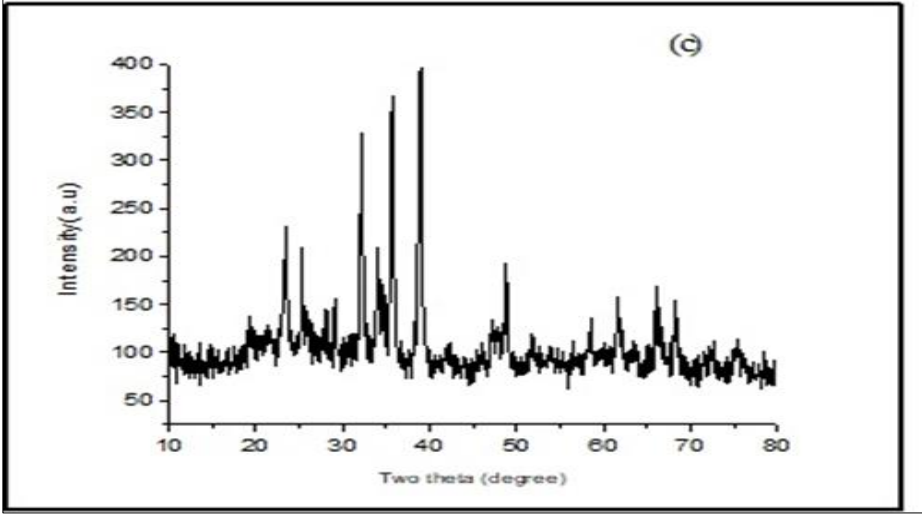

Figure $1 \mathrm{X}$ ray diffraction spectrum of the synthesized $\mathrm{Cu}_{1}$ ${ }_{x} \mathrm{Fe}_{\mathrm{x}} \mathrm{O}$ nanoparticles (a) $\mathrm{x}=0$, (b) $\mathrm{x}=0.1$

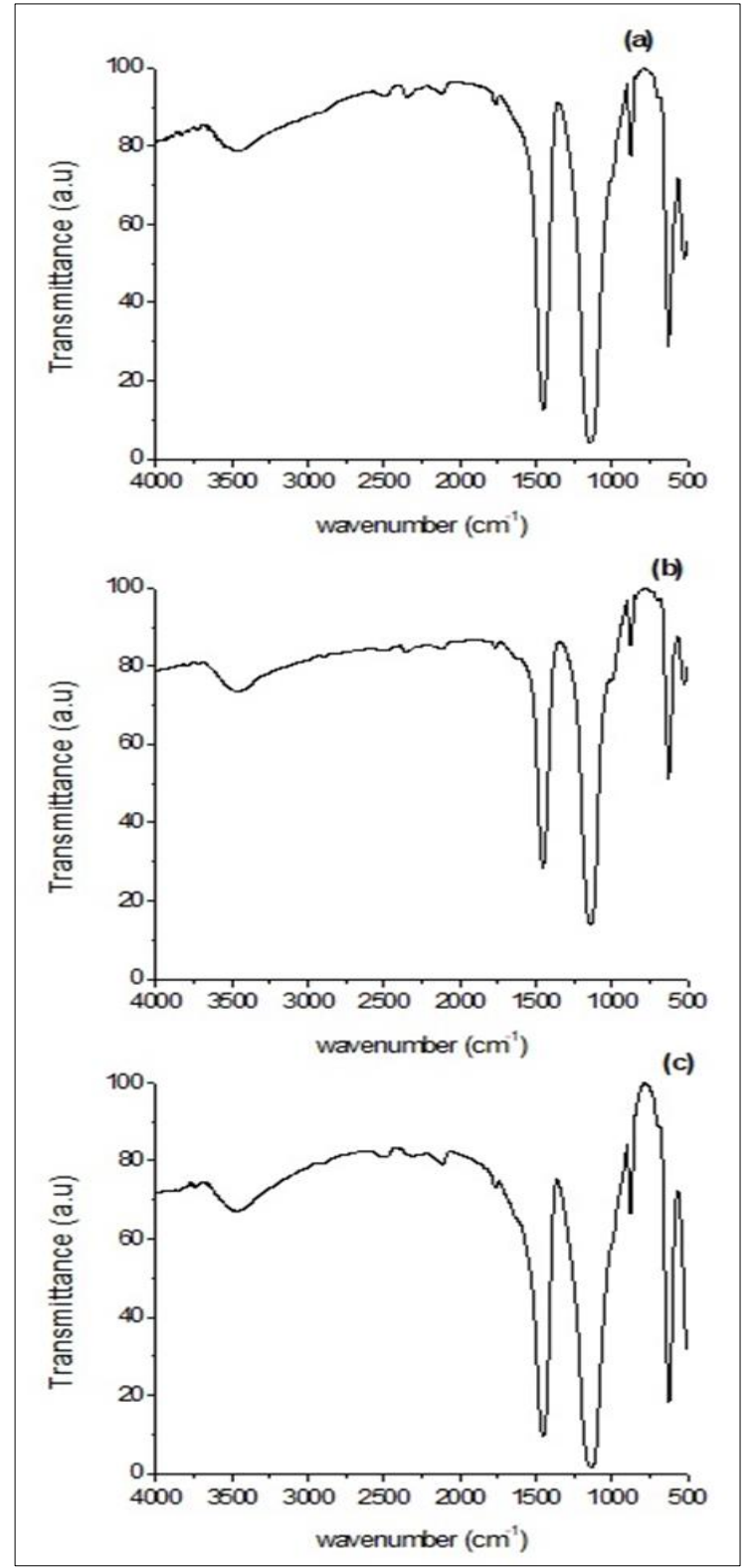

Figure 2 Fourier Infrared spectrum of the synthesized $\mathrm{Cu}_{1-\mathrm{x}} \mathrm{Fe}_{\mathrm{x}} \mathrm{O}$ nanoparticles (a) $\mathrm{x}=0$, (b) $\mathrm{x}=0.05,(\mathrm{c})=0.1$

Table 1 Structural and optical parameters of $\mathrm{Cu}_{1-\mathrm{x}} \mathrm{Fe} \mathrm{e}_{\mathrm{x}} \mathrm{O}(\mathrm{x}=0, \mathrm{x}=0.05, \mathrm{x}=0.1)$

\begin{tabular}{|c|c|c|c|c|}
\hline Sample & Dopant $\mathbf{x}$ & Particle size (nm) & Band gap energy (eV) & Absorption peak (nm) \\
\hline \multirow{4}{*}{$\mathrm{Cu}_{1-\mathrm{x}} \mathrm{Fe}_{\mathrm{x}} \mathrm{O}$} & 0 & 49 & 2.6 & 682 \\
\cline { 2 - 5 } & 0.05 & 42 & 2.7 & 673 \\
\cline { 2 - 5 } & 0.1 & 37 & 2.8 & 616 \\
\hline
\end{tabular}




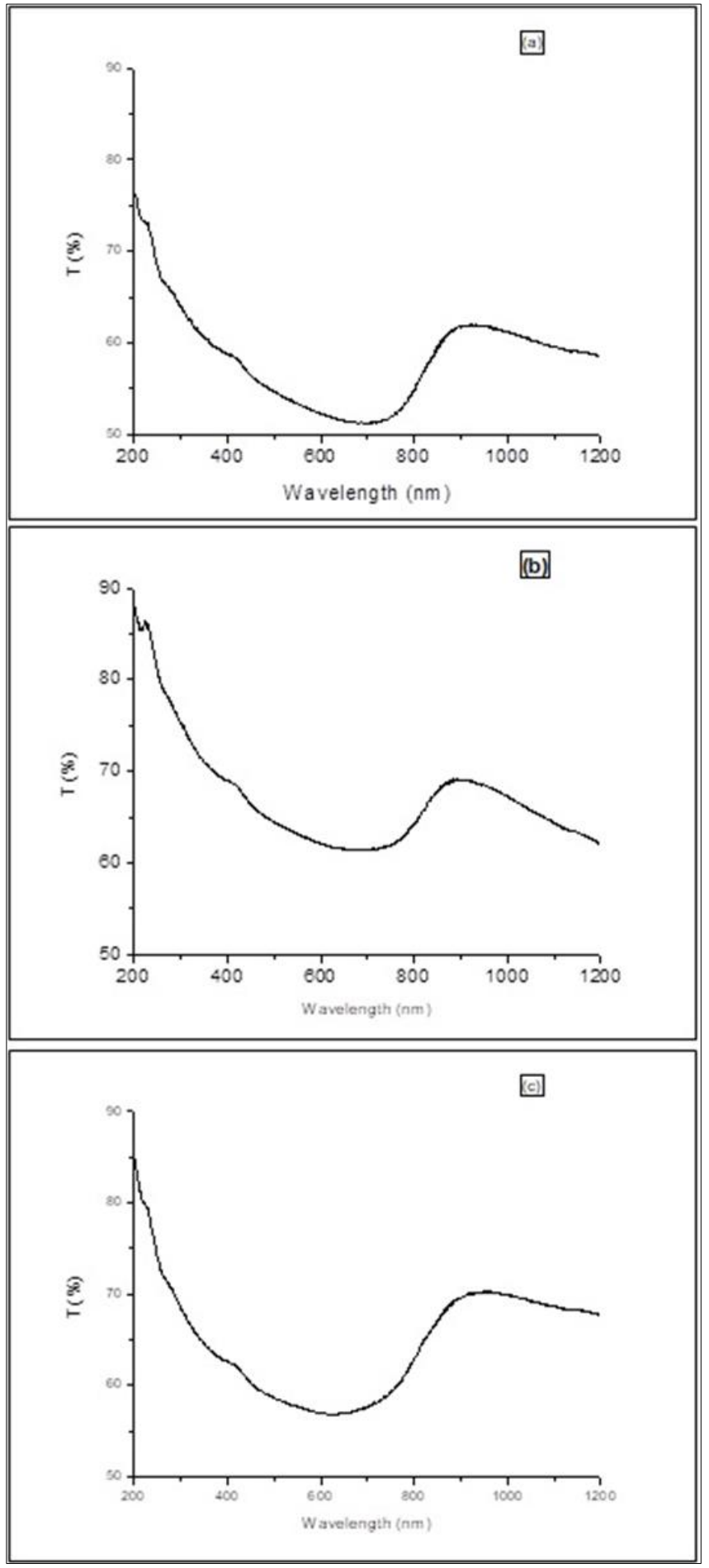

Figure 3 UV-Vis Transmission spectrum of the synthesized $\mathrm{Cu}_{1-\mathrm{x}} \mathrm{Fe}_{\mathrm{x}} \mathrm{O}$ nanoparticles $(\mathrm{a}) \mathrm{x}=0$, (b) $\mathrm{x}=$ $0.05,(c)=0.1$

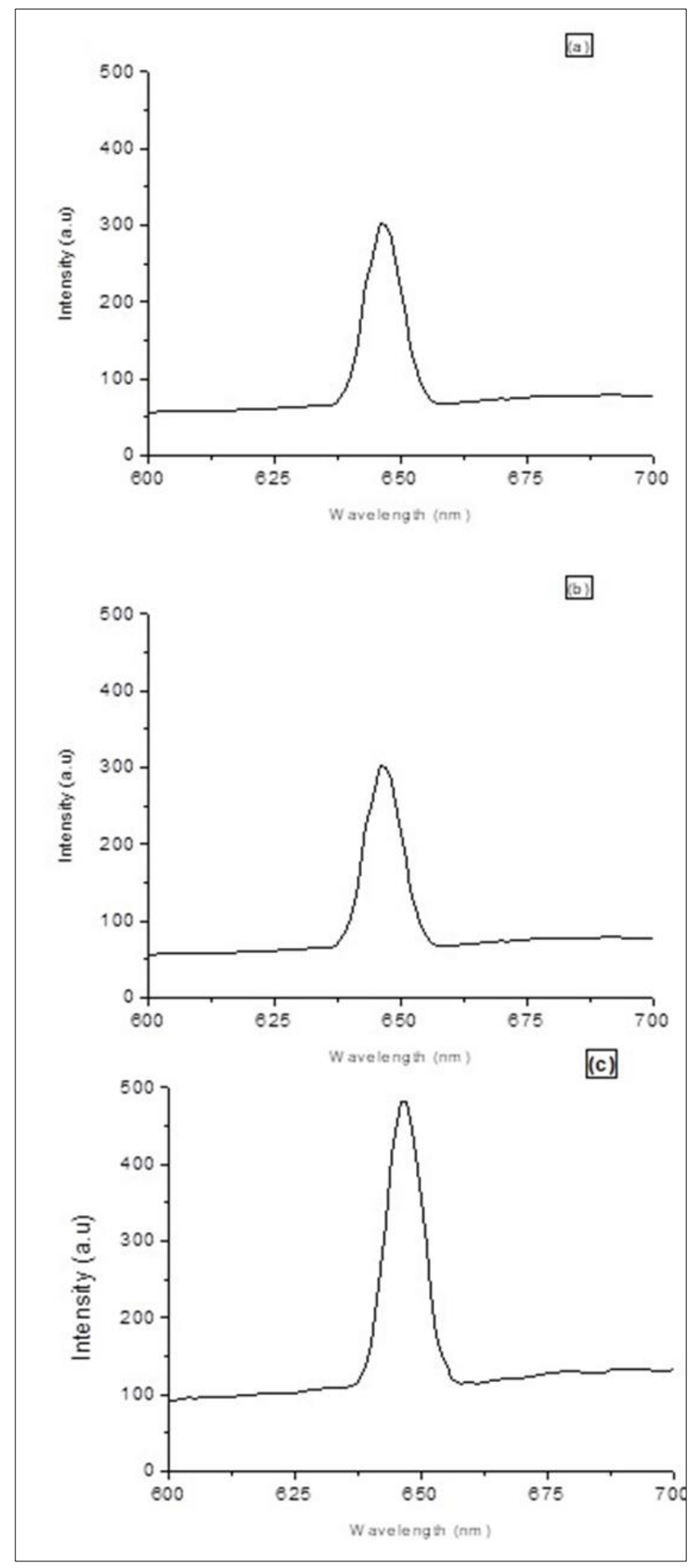

Figure 4 Photoluminescence spectrum of the synthesized $\mathrm{Cu}_{1-\mathrm{x}} \mathrm{Fe}_{\mathrm{x}} \mathrm{O}$ nanoparticles $(\mathrm{a}) \mathrm{x}=0$, (b) $\mathrm{x}=$ $0.05,(c)=0.1$

Calculation infers that the average crystallite size decreases from $49 \mathrm{~nm}$ to $37 \mathrm{~nm}$, as $\mathrm{x}$ goes from 0 to 0.1 . The continuous decrease in the crystallite size with the increase in dopant concentration is due to the presence of the smaller dopant particles into larger particles. Thus, the substitution of Fe is confirmed through the decrease in crystallite size which is shown in Table 1. 


\subsection{FT-IR analysis}

The FT-IR spectroscopy is an essential tool to study the presence of the various functional groups in the synthesized samples. Figure 2 shows the FT-IR spectrum of $\mathrm{Cu}_{1-\mathrm{x}} \mathrm{Fe}_{\mathrm{x}} \mathrm{O}(\mathrm{x}=0.0,0.05$ and 0.1$)$ nano powder. The broad absorption band located at around $3466 \mathrm{~cm}^{-1}$ is attributed to the $\mathrm{O}-\mathrm{H}$ stretching whereas the band at around $1456 \mathrm{~cm}^{-1}$ reveals the symmetric stretching vibration of the C-O band. The absorption band at $1143 \mathrm{~cm}^{-1}$ increases with Fe concentration which is attributed to the $\mathrm{O}-\mathrm{C}-\mathrm{O}$ symmetric and asymmetric stretching vibration. The peak at $633 \mathrm{~cm}^{-1}$ is attributed to $\mathrm{Cu}-\mathrm{O}$ stretching.

\subsection{UV Analysis}

Energy gap (Eg) determination from UV-visible absorption spectrum. The optical absorption properties of synthesized nanoparticles have been analyzed using UV-vis absorption spectrum. It is a suitable method to calculate the energy gap (Eg) of the semiconducting materials which may vary with crystallite size. Figure 3 shows the UV-vis transmission spectrum of the synthesized $\mathrm{Cu}_{1-\mathrm{x}} \mathrm{Fe}_{\mathrm{x}} \mathrm{O}(\mathrm{x}=0,0.05$ and 0.1 ) samples recorded between 190-1100 nm at room temperature. From the transmission spectrum, it can be seen that the transmission varied with dopant concentration. Noticed that the peak absorption is shifted towards the shorter wavelength which represents the blue-shift. The blue shift of the absorption edges and the reduction of band-gap energy reveals the quantum-size effects [24]. The increase in energy gap is the cause of active transitions involving in $3 \mathrm{~d}$ levels of $\mathrm{Cu}$ ions as well as the strong sp-d exchange interaction between the band electron and the localized ' $d$ ' electron of the Fe dopant [25]. The reason for the blue shift can be explained as follows: (i) The nanoparticles absorb the visible light thereby electrons are excited from valence band to conduction band (ii) The interaction between $4 \mathrm{f}$ electrons of $\mathrm{Fe}$ and the conduction band electron of $\mathrm{CuO}$. The wide energy gap of $\mathrm{CuO}(2.8 \mathrm{eV})$ reported here is due to size effect of $\mathrm{CuO}$ nanoparticles. The obtained band energy values are given in Table 1.

\subsection{Photoluminescence spectrum}

The photoluminescence (PL) spectra has given a direct information about the defect present in the materials. Emission property strongly depends upon of the dopant concentration, the morphology of the particles, synthesis method and then the crystallite size. The room temperature PL spectra of $\mathrm{Cu}_{1-\mathrm{x}} \mathrm{Fe}_{\mathrm{x}} \mathrm{O}(\mathrm{x}=0.0,0.05$ and 0.1$)$ nanoparticles is shown in Figure 4. From the figure, it is clear that the enhancement in the intensity of the emission varies linearly with dopant concentration. Generally, the doped $\mathrm{CuO}$ nanoparticles emit UV, violet, blue and green emissions. The UV emission is called as near-band-edge emission which is the result of electron-hole pair recombination in free excitons. The violet emission originates from the defect centers such as $\mathrm{O}$ and $\mathrm{Cu}$ interstitials, the red emission peak observed at $646 \mathrm{~nm}$ attributed to single ionized oxygen vacancy which indicates the recombination of a photon produce hole with a single ionized electron in the valence band. This feature can be explained by the energy transfer between CuO nanoparticles and Fe. From the PL result, it is concluded that the Fe doped $\mathrm{CuO}$ nanoparticles can be used for the design of red emitting optoelectronic devices.

\section{Conclusion}

The $\mathrm{CuO}$ nanostructures and Fe synthesized $\mathrm{CuO}$ nanomaterials are synthesized by microwave irradiation method. The effect of Fe doping on the crystal structure, optical, properties of Synthesized samples were characterized by $\mathrm{x}$-ray diffraction, ultraviolet-visible spectrometer, photoluminescence spectrometer and Fourier transform infrared spectrometer. X-ray diffraction study confirms the size of the particle in nanometer. The optical band gap calculated from UV-Vis absorption spectrum is found to vary between 2.6 and $2.8 \mathrm{eV}$ for undoped and 10 (wt\%) Fe doped samples, respectively. The photoluminescence spectrum suggests that $\mathrm{Fe}$ doped $\mathrm{CuO}$ nanoparticles may be used in optoelectronic devices. The functional group analysis carried out by Fourier transform infrared spectroscopy confirmed the substitution of Fe in the samples.

\section{Compliance with ethical standards}

\section{Acknowledgments}

The author would like to thank the college management for encouragement and permission to carry out this research work.

\section{Disclosure of conflict of interest}

The authors hereby declare there is no conflict of interest. 


\section{References}

[1] Tianmeng Sun, Yu Shrike Zhang, Bo Pang, Dong Choon Hyun, Miaoxin Yang, Younan Xia. Engineered Nanoparticles for Drug Delivery in Cancer Therapy. 2014; 53(46): 12320 -12364.

[2] Goesmann H, Feldmann C. Nanoparticulate Functional Materials. Angew. Chem. Int. Ed. 2010; 49(8): 1362-1395.

[3] Joshua O Ighalo, Patience A Sagboye, Great Umenweke, Oluwaseun J Ajala, Fredrick O Omoarukhe, Comfort A Adeyanju, Samuel Ogunniyi, Adewale G Adeniyi. CuO nanoparticles (CuO NPs) for water treatment: A review of recent advances, Environmental Nanotechnology, Monitoring \& Management. 2021; 15: 100443.

[4] Qiaobao Zhang, Kaili Zhang, Daguo Xu, Guangcheng Yang, Hui Huang, Fude Nie, Chenmin Liu, Shihe Yang. CuO nanostructures: Synthesis, characterization, growth mechanisms, fundamental properties, and applications, Progress in Materials Science. 2014; 60: 208-337.

[5] Mejda Ajili, Najoua Turki Kamoun. Structural and optoelectronic studies of CuO, In2-xAlxS3 and SnO2: F sprayed thin films for solar cell application: Au/CuO (p)/In2-xAlxS3 (n)/SnO2:F, Optik. 2021; 229: 166222.

[6] Saraswati Kulkarni, Ruma Ghosh, A simple approach for sensing and accurate prediction of multiple organic vapors by sensors based on CuO nanowires, Sensors and Actuators B: Chemical. 2021; 335: 129701.

[7] Chang J, Waclawik ER. Colloidal semiconductor nanocrystals: Controlled synthesis and surface chemistry in organic media. RSC Adv. 2014; 4(45): 23505-23527.

[8] Kamat P.V. Photophysical, Photochemical and Photocatalytic Aspects of Metal Nanoparticles. J. Phys. Chem. B. 2002; 106(32): 7729-7744.

[9] Daniel MC, Astruc D. Gold Nanoparticles: Assembly, Supramolecular Chemistry, Quantum-Size-Related Properties, and Applications toward Biology, Catalysis, and Nanotechnology. Chem. Rev. 2004; 104(1): 293-346.

[10] Schimpf S, Lucas M, Mohr C, Rodemerck U, Brückner A, Radnik J, Hofmeister H, Claus P. Supported gold nanoparticles: in-depth catalyst characterization and application in hydrogenation and oxidation reactions. Catal. Today. 2002; 72(1-2): 63-78.

[11] Mahmood ulhaq, Muzaffar Iqbal, Muhammad Aurag Zeb GulSial, Saima Shabbir, Muhammad Siddiq, AzharIqbal. Effect of Fe doping on the crystallinity of $\mathrm{CuO}$ nanotubes and the efficiency of the hybrid solar cells, Journal of Photochemistry and Photobiology A: Chemistry. February 2017; 335: 112-118.

[12] M Ponnar, C Thangamani, P Monisha, SS Gomathi, K Pushpanathan. Influence of Ce doping on CuO nanoparticles synthesized by microwave irradiation method, Applied Surface Science. 2018; 449: 132-143.

[13] L Vimala Devi, S Sellaiyan, T Selvalakshmi, HJ Zhang, A Uedono, K Sivaji, S Sankar. Synthesis, defect characterization and photocatalytic degradation efficiency of $\mathrm{Tb}$ doped $\mathrm{CuO}$ nanoparticles, Advanced Powder Technology. November 2017; 28(11): 3026-3038.

[14] N Mohamed Basith, J Judith Vijaya, L John Kennedy, M Bououdina. Structural, optical and room-temperature ferromagnetic properties of Fe-doped $\mathrm{CuO}$ nanostructures, Physica E: Low-dimensional Systems and Nanostructures. September 2013; 53: 193-199.

[15] TariqJan, J Iqbal, Umar Farooq, Asma Gul, Rashda Abbasi, Ishaq Ahmad, Maaza Malik. Structural, Raman and optical characteristics of $\mathrm{Sn}$ doped $\mathrm{CuO}$ nanostructures: A novel anticancer agent, Ceramics International. December 2015; 41(10): 13074-13079.

[16] Petr Vomáčka, Václav Štengl, Jiří Henych, MartinKormunda. Shape-controlled synthesis of Sn-doped CuO nanoparticles for catalytic degradation of Rhodamine B, Journal of Colloid and Interface Science. 2016; 481: 2838.

[17] K Rayapa Reddy. Green synthesis, morphological and optical studies of CuO nanoparticles, Journal of Molecular Structure. 2017; 1150: 553-557.

[18] L Vimala Devi, T Selvalakshmi, S Sellaiyan, A Uedono, K Sivaji, S Sankar. Effect of La doping on the lattice defects and photoluminescence properties of CuO, Journal of Alloys and Compounds. 2017; 709: 496-504.

[19] J Sivasankari, S Selvakumar Sellaiyan, S Sankar, L Vimala Devi, K Sivaji. Structural and optical characterization of Er-alkali-metals codoped MgO nanoparticles synthesized by solution combustion route, Physica E: Lowdimensional Systems and Nanostructures. 2017; 85: 152-159. 
[20] Zhao J, Liu Y, Pan B, Gao G, Liu Y, Liu S, Liang N, Zhou D, Vijver MG, Peijnenburg WJGM. Tannic acid promotes ion release of copper oxide nanoparticles: Impacts from solution $\mathrm{pH}$ change and complexation reactions, Water Research. 2017; 127.

[21] MotaharehDarvishi, GhafarMohseni-Asgerani, JamilehSeyed-Yazdi. Simple microwave irradiation procedure for the synthesis of $\mathrm{CuO} /$ Graphene hybrid composite with significant photocatalytic enhancement, Surfaces and Interfaces. June 2017; 7: 69-73.

[22] D Gao, J Zhang, J Zhu, Q Jing, Z Zhang, S Wenbo, S Huigang, D Xue. Nanoscale Res. Lett. 2010; 5: 769.

[23] P Scherrer. Nachr. Ges. Wiss. Göttingen. 1918; 26: 98-100.

[24] LF Koao, BF Dejene, HC Swart, TE Motaung. Inter. J. Lumin. Appln. 2015; 5: 54-61.

[25] M Farhadi-Khouzani, Z Fereshteh, MR Loghman-Estarki, RS Razavi, J Sol-Gel Sci. Tech. 2012; 64: 193-199. 